\title{
СРАВНЕНИЕ ВАРИАНТОВ ПРОФИЛАКТИКИ ОККЛЮЗИИ ЛУЧЕВОЙ АРТЕРИИ ПРИ ВЫПОЛНЕНИИ ЧРЕЗКОЖНОГО КОРОНАРНОГО ВМЕШАТЕЛЬСТВА В РАЗЛИЧНЫЕ ВРЕМЕННЫЕ ПРОМЕЖУТКИ
}

\section{COMPARISON OF OPTIONS \\ FOR PREVENTION OF RADIAL ARTERY \\ OCCLUSION DURING PERCUTANEOUS CORONARY INTERVENTION AT DIFFERENT TIME INTERVALS}

N. Peskov

Summary. This scientific study reveals the most effective method of preventing damage to the radial artery when performing diagnostic coronary angiography and percutaneous coronary intervention. These patients were divided into 3 groups depending on the chosen method of prevention of damage to the radial artery. We proved that the use of controlled compression of the radial artery with special bracelets was most effective in contrast to the other two methods of prevention. Also, during the study, special devices were developed for hemostasis of the radial and femoral artery puncture site, which are being actively implemented in medical practice.

Keywords: occlusion, TR-Band, therapeutic and diagnostic coronary interventions.

\section{Актуальность исслеАования}

Д анная работа раскрывает различные подходы к предупреждению окклюзии лучевой артерии, такие как:

1. использование гепарина совместно с препаратами, уменьшающими вазоспазм;

2. ипсилатеральная временная окклюзия локтевой артерии;

3. использование контролируемой компрессии лучевой артерии специальными браслетами.

Перед рентгенэдоваскулярными хирургами стоит не простая задача в сохранении нормально функционирующей лучевой артерии, в связи с тем, что после установки стента в коронарную артерии, больному кроме приема антиагрегантов также необходимо проведения повторного диагностического исследования «коронарографии» для контроля состояния коронарных артерии и функции самого стента, после его установки. В отече-
Песков Николай Андреевич

Аспирант, Ростовский государственный медицинский университет Министерства здравоохранения Российской Федерации,

Ростов-на-Дону

nap_medic@bk.ru

Аннотация. Данное научное исследование выявляет наиболее эффективный метод профилактики повреждения лучевой артерии при выполнении диагностической коронароангиографии и чрезкожного коронарного вмешательства. Данные больные были разбиты на 3 группы в зависимости от выбранного метода профилактики повреждения лучевой артерии. Нами было доказано, что использование контролируемой компрессии лучевой артерии специальными браслетами, оказалось наиболее эффективно в отличие от двух других методов профилактики. Также в ходе исследования были разработаны специальные устройства для гемостаза места пункции лучевой и бедренной артерий, которые активно внедряются в медицинскую практику.

Ключевые слова: окклюзия, TR-Band, лечебно-диагностические коронарные вмешательства.

ственной и зарубежной литературе очень мало данных об отдаленных результатах различных подходов к профилактике окклюзии лучевой артерии в результате трансрадиальных лечебно-диагностических коронарных вмешательств, а также практически отсутствуют данные о сравнении результатов различных методик профилактике окклюзии лучевой артерии. Выполнение же коронарографии через бедренную артерию связано с неоднократным прохождением катетеров через все отделы аорты. При необходимости визуализации других сосудистых бассейнов (брахиоцефальные артерии и др.) количество манипуляций с катетерами увеличивается. При многократном прохождении через пораженный отдел аорты эндоваскулярных инструментов вероятность дислокации тромботических масс и возникновения тромбоэмболии существенно возрастает. Перемещением атероматозных фрагментов вместе с катетером в грудные отделы аорты можно объяснить более частое возникновение ишемических инсультов у больных с аневризмой брюшной аорты и тромботическими массами в ее поло- 
сти при выполнении коронарографии бедренным доступом [1, 2]. При выполнении обследования радиальным доступом у таких больных необходимость проведения катетеров через все отделы аорты отпадает, что существенно снижает риск дислокации тромботических масс. При радиальном доступе катетер из подключичной артерии попадает сразу в восходящий отдел грудной аорты. Частота атеросклеротического поражения грудного отдела аорты существенно ниже, чем брюшного. По количеству осложнений в месте пункции бедренный доступ намного проблематичен нежели радиальный [3].

\section{Цель работы}

Основная цель данного научного исследования: выявить наиболее эффективные методы профилактики окклюзии лучевой артерии при выполнении трансрадиальных лечебно-диагностических коронарных вмешательств, выбрав из трех методов профилактики окклюзии лучевой артерии наиболее эффективный и безопасный.

\section{Материалы и метолы}

Проведен проспективный анализ результатов применения методов профилактики окклюзии лучевой артерии после трансрадиальной аортокоронарографии. В исследовании приняли участие 1000 пациентов (с сентября 2016 г по март 2019 г) с атеросклерозом коронарных артерий и клиникой ишемической болезни сердца с наличием гемодинамически значимого стеноза коронарных артерий (более 50\% диаметра сосуда). Согласно используемым методам профилактики окклюзии лучевой артерии пациенты разделены на 3 группы:

1 группа ( $n=230)$ - интраоперационное введение гепарина (5000 ЕД) + асептическая бинтовая давящая повязка.

2 группа: ( $n=230)$ - ипсилатеральная временная окклюзия локтевой артерии.

3 группа: ( $\mathrm{n}=240)$ - контролируемая компрессии ЛА специальными браслетами после введение 5000 ЕД гепарина.

Исследование проводится с сентября 2016 года на базах Кардиохирургического центра ГБУ РО «Ростовская областная клиническая больница», отделения рентгенхирургических методов диагностики и лечения № 2 МБУЗ КДЦ «Здоровье», отделения хирургического лечения сложных нарушений ритма сердца и электрокардиостимуляции ГБУЗ СК «КККД» г. Ставрополь. Статистическая обработка данных проводилась при помощи программы STATISTICA 8.0. Также в ходе проведения исследования были разработаны устройства для осуществления гемостаза места пункции лучевой и бедренной артерии после выполнения коронарографии [4, 5].

\section{Результаты исслеАования}

В первые сутки у больных, которым была произведена пункция лучевой артерии в типичном месте с последующим введением после установки трансрадиального 6F интродьюсера Змл 0.5\% р-ра нитроглицерина и последующим наложением асептической давящей повязки на 24 часа по окончании выполнения коронароангиографии. Окклюзия лучевой артерии произошла у трех пациентов, что составило 1,3\% от общего количества больных в данной группе пациентов в конкретном промежутке времени (ранний постоперационный период). Профилактика окклюзии лучевой артерии этим же способом в разные временные промежутки показала результаты. Окклюзия лучевой артерии произошла у трех человек через 30 дней, что составило также 1.3\%. И через год окклюзия в этой группе больных была выявлена у $2-x$ человек, что составило $0.86 \%$.

В итоге, используя данный метод профилактики окклюзии лучевой артерии, получены результаты, при которых в разные временные промежутки окклюзия лучевой артерии произошла у 8 пациентов из общего числа пациентов данной группы, что составило $3.47 \%$

Рассмотрев вторую группу пациентов, в которой мы использовали в качестве основного метода профилактики повреждения лучевой артерии это проведение ипсилатеральной контролируемой окклюзии локтевой артерии, были получены следующие результаты. Окклюзия лучевой артерии произошла в первые сутки после выполнения трансрадиальной лечебно- диагностической коронарографии у трех человек из общего количества пациентов, что составило 1.3\%, через 30 дней диагностирована окклюзия у двух пациентов, что составило 0.86\%. Однако при исследовании полученных результатов в группе пациентов через 1 год после выполненной коронароангиографии, нами было получены результаты, при которых окклюзия ранее пунктрированной лучевой артерии произошла у одного человека, что составило $0.43 \%$. В сумме окклюзия лучевой артерии в данной группе пациентов произошла у 6-ти человек от общего количества пациетов, что составило 2.60\%. Данный результат оказался меньше, чем в группе пациентов, у которых использовалась компрессия лучевой артерии асептической давящей повязкой на 24 часа. В третьей же группе пациентов, у которых мы использовали временную компрессия лучевой артерии совместно с применением 0.5\% раствора нитрогицерина после установки трансрадиального интродьюсера 6F- окклюзия лучевой артерии возникла в первой временной группе у одного человека от общего числа пациентов в данной группе, в конкретном временном промежутке, что составило $0.42 \%$. Во второй группе не обнаружено пациентов с окклюзией лучевой артерии. В третьей же 
группе наших пациентов был также, как и первой группе один случай окклюзии лучевой артерии, что составило $0.42 \%$. При этом общее количество окклюзий лучевой артерии в данной группе произошло у 2-х человек, что составило $0.84 \%$, что достоверно меньше относительно 1 и 2 группы $(p<0,05)$.

Учитывая полученные нами результаты и проведенный нами сравнительный анализ трех методов профилактики окклюзии лучевой артерии после выполнения коронароангиографии и чрезкожного коронарного вмешательства, можно с достоверно говорить, что все три метода профилактики окклюзии лучевой артерии показали себя вполне дееспособными, что может говорить о том, что все три метода профилактики можно использовать. Однако наилучшие результаты оказались в группе, где использовалась временная контролируемая компрессия области пункции лучевой артерии специ- альными компрессионными устройствами (TR-Band). Поэтому использование данного метода профилактики окклюзии лучевой артерии, является наилучшим выбором у практикующих интервенционных хирургов.

\section{Зак^ючение}

Согласно полученным данным, после проведения трансрадиальной аортокоронарографии в профилактике окклюзии лучевой артерии эффективней всего себя проявил метод совместного использования гепарина 5000 ЕД с последующей контролируемой компрессией лучевой артерии при помощи TR-band, так как при данном методе процент окклюзии лучевой артерии был наименьшим (0,84\%). В связи с этим данный метод профилактики окклюзии лучевой артерии является наиболее перспективным при выполнении трансрадиальных лечебно-диагностических коронарных вмешательств.

\section{ЛИТЕРАТУРА}

1. Anderson S.G., Ratib K., Myint P. K., Keavney B., Kwok C. S., Zaman A., Ludman P. F., de Belder M. A., Nolan J., Mamas M. A. Impact of age on access site-related outcomes in 469,983 percutaneous coronary intervention procedures: insights from the British Cardiovascular Intervention Society // Catheter Cardiovasc Interv. 2015. № 86. Pp. 965-972.

2. Feldman D.N., Swaminathan R.V., Kaltenbach L. A., Baklanov D.V., Kim L. K., Wong S.C., Minutello R. M., Messenger J. C., Moussa I., Garratt K. N., Piana R. N., Hillegass W. B., Cohen M. G., Gilchrist I.C., Rao S.V. Adoption of radial access and comparison of outcomes to femoral access in percutaneous coronary intervention the National Cardiovascular Data Registry (2007-2012). Circulation. 2013. № 127. Pp. 2295-2306.

3. Kotowycz M.A., Johnston K.W., Ivanov J., Asif N., Almoghairi A. M., Choudhury A., Nagy C. D., Sibbald M., Chan W., Seidelin P. H., Barolet A.W., Overgaard C. B., Džavík V. Predictors of radial artery size in patients undergoing cardiac catheterization: insights from the Good Radial Artery Size Prediction (GRASP) study // Can J Cardiol. 2014. № 30 (2). Pp. 211-6. doi: 10.1016/j.cjca.2013.11.021.

4. Устройство для осуществления гемостаза в пункционном отверстии бедренной артерии. Патент на изобретение РФ№ 2635081 08.11.2017, Бюл. № 31, 9 с.

5. Устройство для осуществления гемостаза пункции лучевой артерии. Патент на изобретение РФ № 2659023 26.06.2018, Бюл. № 18, 10 с. 